\title{
Article \\ Interactions of Vallisneria natans and Iron-Oxidizing Bacteria Enhance Iron-Bound Phosphorus Formation in Eutrophic Lake Sediments
}

\author{
Juanjuan Wang ${ }^{1}$, Mingming Gao ${ }^{1}$, Yanju Yang ${ }^{1}$, Shipeng Lu ${ }^{2}$, Guiliang Wang ${ }^{1, *}$ and Xiaoqing Qian ${ }^{1,3, *}$ \\ 1 College of Environmental Science and Engineering, Yangzhou University, Yangzhou 225127, China; \\ wangjuanjuan@yzu.edu.cn (J.W.); gm15161936801@163.com (M.G.); 006468@yzu.edu.cn (Y.Y.) \\ 2 Institute of Botany, Jiangsu Province and Chinese Academy of Sciences, Nanjing 210014, China; \\ lvshipeng@cnbg.net \\ 3 Jiangsu Collaborative Innovation Center for Solid Organic Waste Resource Utilization, Nanjing 210014, China \\ * Correspondence: wg10520@yzu.edu.cn (G.W.); qianxq@yzu.edu.cn (X.Q.)
}

check for updates

Citation: Wang, J.; Gao, M.; Yang, Y.; Lu, S.; Wang, G.; Qian, X. Interactions of Vallisneria natans and Iron-Oxidizing Bacteria Enhance Iron-Bound Phosphorus Formation in Eutrophic Lake Sediments.

Microorganisms 2022, 10, 413.

https://doi.org/10.3390/

microorganisms10020413

Academic Editor: Spiros N

Agathos

Received: 29 December 2021

Accepted: 1 February 2022

Published: 11 February 2022

Publisher's Note: MDPI stays neutral with regard to jurisdictional claims in published maps and institutional affiliations.

Copyright: (C) 2022 by the authors. Licensee MDPI, Basel, Switzerland. This article is an open access article distributed under the terms and conditions of the Creative Commons Attribution (CC BY) license (https:// creativecommons.org/licenses/by/ $4.0 /)$.

\begin{abstract}
Submerged macrophyte restoration and in situ phosphorus $(\mathrm{P})$ passivation are effective methods for the control of internal P loading from sediments. This study explored the synergistic effects of Vallisneria natans and iron (Fe)-oxidizing bacteria (IOB) on internal P loading from eutrophic freshwater lake sediments by taking into account Fe-bound $\mathrm{P}(\mathrm{FeP})$ formation and associated bacterial community structures. Sediment samples were prepared in glass tanks under four treatments, namely no $V$. natans planting or IOB inoculation (control), planting $V$. natans without IOB inoculation (Va), planting $V$. natans with IOB inoculation (Va-IOB), and planting $V$. natans with autoclaved IOB inoculation (Va-IOB[A]). Compared with the control, all three treatments with V. natans (Va, Va-IOB, and $\mathrm{Va}-\mathrm{IOB}[\mathrm{A}]$ ) had significantly decreased organic matter contents and increased redox potential in sediments $(p<0.05)$, at the rapid growth and mature stages of $V$. natans. Planting $V$. natans with and without IOB inoculation also decreased the total $\mathrm{P}(\mathrm{TP})$ and $\mathrm{Fe}-\mathrm{P}$ concentrations in sediments. Conversely, $\mathrm{Fe}^{3+}$ concentrations, $\mathrm{Fe}^{3+} / \mathrm{Fe}^{2+}$ ratios, and the proportions of $\mathrm{Fe}-\mathrm{P}$ in TP all increased in sediments planted with $V$. natans, especially under the Va-IOB treatment $(p<0.05)$. Furthermore, bacterial community diversity increased in sediments due to the presence of $V$. natans. The relative abundances of IOB (including Acidovorax and Chlorobium) increased from the transplanting to the rapid growth stage of $V$. natans and then decreased afterwards. In the later stages, the relative abundances of IOB and their ratios to Fe-reducing bacteria were the highest under the Va-IOB treatment. Accordingly, synergistic interactions between $V$. natans and IOB could enhance Fe-P formation and reduce TP concentrations in eutrophic lake sediments by altering sediment physicochemical properties and Fe oxidation-related bacterial community structures.
\end{abstract}

Keywords: bacterial community structure; bacterially mediated iron oxidation; eutrophic lake sediments; iron-bound phosphorus; Vallisneria natans

\section{Introduction}

Eutrophication of freshwater bodies is caused primarily by excess nutrient inputs, especially phosphorus $(\mathrm{P})$. $\mathrm{P}$ is considered the key limiting nutrient in the water eutrophication process, with nitrogen $(\mathrm{N})$ being the second most important element [1]. Controlling external $\mathrm{P}$ input has been proposed as one of the main strategies of mitigating eutrophication in lakes [2]. However, P release from surface sediments often leads to delayed recovery of freshwater from eutrophication following the reduction of external $P$ input [3]. Consequently, the control of internal P loading from sediments has increasingly attracted the attention of researchers and stakeholders in eutrophication management in freshwater ecosystems.

Among the numerous water remediation technologies, submerged macrophyte restoration and in situ P passivation are two effective methods of controlling internal P loading. 
For example, the common macrophyte Vallisneria natans (eelgrass) can absorb P and N from the water column and surface sediments [4-6]. In addition, submerged macrophytes increase sediment redox potential (Eh), which in turn enhances P retention in sediments and reduces its release into the water column [7]. Submerged macrophytes are distributed extensively in freshwater environments and can be obtained relatively easily; consequently, they represent ideal natural materials for controlling internal P loading from sediments. In addition, the efficiency of submerged macrophytes in controlling internal P loading may be enhanced by integration with in situ P passivation [8,9].

The adsorption technique has shown tremendous potential for in situ P passivation in sediments, with widespread use and simple operation [6,10]. Adding absorbents such as iron $(\mathrm{Fe})$ compounds could enhance P retention in the sediment and limit the increase in dissolved $\mathrm{P}$ concentration in the water column. Li et al. [11] found that the addition of ferric chloride could convert $\mathrm{P}$ into more stable organic forms and could effectively inhibit the release of internal $\mathrm{P}$ from the sediment. Furthermore, Fe-modified calcite, as an adsorption material, could remove $91.7 \%$ of $P$ from the water column and maintain $90.8 \%$ of sediment $P$ in a stable state, reducing the potential of $P$ release from sediments [12]. In situ P passivation techniques, however, have some limitations. For example, large-scale applications of adsorbents for passivizing $\mathrm{P}$ in sediments often have high manufacturing and transportation costs.

Microbial remediation of polluted environments has broad application prospects considering its simple operation, low cost, high efficiency, and minimal impacts on the environment [13,14]. An improved in situ P passivation method involves inoculation of sediment with functional microorganisms that participate in Fe redox transformation; in this way, Fe redox speciation can be used to regulate $\mathrm{P}$ transfer between the sediment and water column [7]. In shallow eutrophic lakes, P retention in sediments has been reported to be controlled mainly by the oxidation of $\mathrm{Fe}^{2+}$ [15]. Iron-oxidizing bacteria (IOB) can oxidize $\mathrm{Fe}^{2+}$ into $\mathrm{Fe}^{3+}$ and form Fe oxides such as ferric hydroxide $(\mathrm{FeOOH})$ colloids. The $\mathrm{FeOOH}$ colloids have a high $\mathrm{PO}_{4}{ }^{3-}$ absorption capacity and promote the formation of Fe-bound $\mathrm{P}$ (Fe-P) [16].

Generally, Fe-P refers to the $\mathrm{P}$ adsorbed on the surface of $\mathrm{FeOOH}$ by physical or chemical actions [17], and its release process is influenced by multiple environmental factors, such as $\mathrm{pH}$ and $\mathrm{Eh}[18,19]$. When Eh decreases, $\mathrm{Fe}^{3+}$ is reduced to $\mathrm{Fe}^{2+}$, leading to $\mathrm{FeOOH}$ dissolution and the subsequent release of Fe-P; conversely, high Eh results in $\mathrm{Fe}^{2+}$ oxidation into $\mathrm{Fe}^{3+}$ and facilitates $\mathrm{Fe}-\mathrm{P}$ formation [20]. Numerous studies have focused either on the reduction in P concentration (by submerged macrophyte restoration) [4-6] or the passivation of $\mathrm{P}$ (by microbial inoculation) in sediments [7,13-15]. However, few studies have explored the synergistic effects of submerged macrophyte restoration and microbial inoculation on $\mathrm{Fe}-\mathrm{P}$ formation and $\mathrm{P}$ retention in sediments.

In the present study, sediments were sampled from a highly eutrophic freshwater lake and subjected to combinations of $V$. natans planting and IOB inoculation treatments. The objective was to explore the synergistic effects of $V$. natans and IOB on Fe-P distribution and to reveal the mechanisms of $\mathrm{Fe}-\mathrm{P}$ formation in eutrophic lake sediments. Our hypotheses were as follows: (1) synergistic interactions between $V$. natans growth and IOB activity enhance Fe-P formation and reduce $\mathrm{P}$ concentrations in sediments; and (2) the introduction of $V$. natans and IOB alters the structure of sediment bacterial communities that mediate $\mathrm{P}$ retention. The results of the present study provide scientific evidence that could facilitate the control of internal P loading from freshwater sediments based on an integrated and environmentally friendly technology.

\section{Materials and Methods}

\subsection{Experimental Materials}

We selected $V$. natans, a widely distributed submersed macrophyte, as the experimental material. V. natans seedlings were collected from Qinhu Lake $\left(32^{\circ} 37^{\prime} \mathrm{N}, 120^{\circ} 09^{\prime} \mathrm{E}\right)$ in Taizhou (Jiangsu Province, China), a eutrophic lake under ecological restoration. After 
15 days of acclimation in a simulated lake system, the seedlings were rinsed thoroughly with distilled water.

Glass tanks ( $30 \mathrm{~cm}$ high $\times 15 \mathrm{~cm}$ wide $\times 15 \mathrm{~cm}$ long) were used to simulate the lake system (Figure 1), using sediment and water samples collected from the sampling site of $V$. natans seedlings. On 9 September 2020, surface water was collected from the lake at a depth of $0-20 \mathrm{~cm}$, and 20 replicate sediment cores $(15 \mathrm{~cm}$ inner diameter $\times 30 \mathrm{~cm}$ long) were collected using a gravity corer $(15 \mathrm{~cm}$ diameter $\times 50 \mathrm{~cm}$ long; Rigo Co., Saitama, Japan). All of the sediment samples were mixed thoroughly with appropriate amounts of lake water and filtered through a $0.2 \mathrm{~cm}$ sieve to remove coarse debris. After homogenization, the sediment was transferred into glass tanks followed by lake water, yielding a $10 \mathrm{~cm}$ layer of sediment and $15 \mathrm{~cm}$ of overlying water.

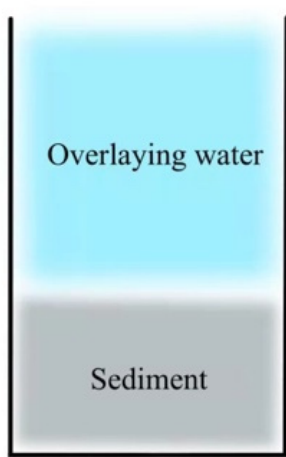

Ctrl

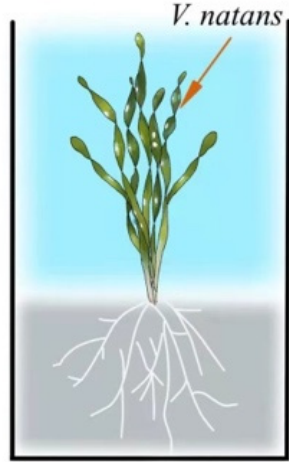

Va

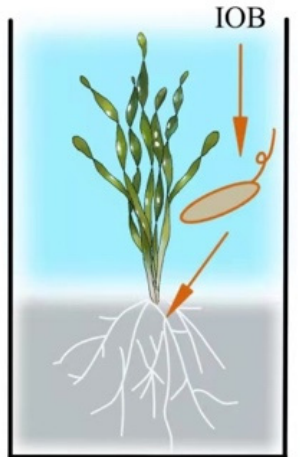

Va-IOB

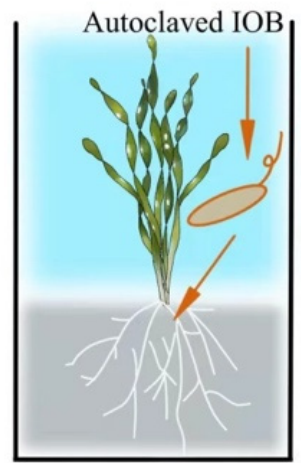

Va-IOB(A)

Figure 1. Overview of the experimental setup and treatment arrangement. Ctrl, no V. natans planting or iron-oxidizing bacteria (IOB) inoculation; Va, planting $V$. natans without IOB inoculation; Va-IOB, planting $V$. natans with IOB inoculation; Va-IOB(A), planting V. natans with autoclaved IOB inoculation.

An improved gradient tube method was used to obtain IOB [21]. First, the inoculum was prepared by vortexing a mixture containing $10 \mathrm{~mL}$ of sterilized deionized water and $1 \mathrm{~g}$ of sediment sample from Qinhu Lake for approximately $30 \mathrm{~min}$. Subsequently, an opposite gradient of oxygen and $\mathrm{Fe}^{2+}$ (as FeS) was generated in glass bottles (50 mm high $\times 16 \mathrm{~mm}$ diameter). The inoculum $(100 \mu \mathrm{L}$ each) was inoculated along the vertical axis of the gradient tubes at serial dilutions $\left(10^{-1}\right.$ to $\left.10^{-5}\right)$ to allow for the growth of IOB at the artificial oxic-anoxic interface. The gradient tubes were incubated at $25^{\circ} \mathrm{C}$ in the dark. On the second day after the formation of solid-phase Fe oxide bands (1st generation), approximately $10 \%$ of the band was extracted from the gradient tubes with the highest dilution of inoculum and then inoculated into a fresh gradient tube. The process was repeated over a two-week period for six generations to enrich IOB.

\subsection{Experimental Design}

There were four experimental treatments (Figure 1), namely no $V$. natans planting or IOB inoculation (control), $V$. natans planting without IOB inoculation (Va), V. natans planting with IOB inoculation (Va-IOB), and $V$. natans planting with autoclaved IOB inoculation (Va-IOB[A]). Each treatment had four replicates (glass tanks).

Acclimated $V$. natans seedlings were transplanted into glass tanks on 12 September 2020. With the exception of the control treatment, three plants were transplanted to the center of each tank after filling with water. All tanks were set up in an open room with a transparent roof and were exposed to natural sunlight. During the experimental period (12 September 2020-25 December 2020), the indoor temperature was maintained at $18{ }^{\circ} \mathrm{C}$ on average. An appropriate amount of sterilized deionized water was added to each tank once every three days to maintain the initial water level.

IOB inoculation was conducted in the early rapid growth stage of $V$. natans (four weeks after transplanting). In brief, IOB-containing bands were collected from one-week- 
old culture in gradient tubes with a sterile syringe $(20 \mathrm{~mL})$, thoroughly mixed, and divided into two portions. One portion was used directly for Va-IOB treatment, while the other portion was autoclaved at $121{ }^{\circ} \mathrm{C}$ for $30 \mathrm{~min}$ to kill the bacteria and then used for VaIOB(A) treatment. The colloidal solution containing IOB (autoclaved or not, $5 \mathrm{~mL}$ each) was inoculated into the sediment layer in glass tanks at a $5 \mathrm{~cm}$ depth through a sterilized syringe $(10 \mathrm{~mL})$.

\subsection{Sediment Physicochemical Analysis}

Sediment samples (30 g each) were collected from each glass tank using a custom-made columnar mud collector (1 cm diameter) on the transplanting day (12 September 2020), rapid growth stage (28 October 2020), and mature stage of $V$. natans (25 December 2020). Each sediment sample was immediately divided into three subsamples. One subsample was air-dried and passed through a $0.15 \mathrm{~mm}$ sieve for use in the determination of conventional physicochemical properties. The second subsample was vacuum freeze-dried at $-50^{\circ} \mathrm{C}$ for use in the determination of Fe content. The third subsample was immediately stored in a refrigerator at $-80^{\circ} \mathrm{C}$ until use for bacterial community analysis.

Sediment $\mathrm{pH}$ and Eh were measured in situ using a portable $\mathrm{pH}$ meter (PHB-4; Leici, Shanghai, China) and an Eh meter (SX712; Ruisun, Chengdu, China), respectively [9]. Organic matter $(\mathrm{OM})$ content in sediments was determined based on wet combustion with $\mathrm{K}_{2} \mathrm{Cr}_{2} \mathrm{O}_{7}$, and measured through titration with $\left(\mathrm{NH}_{4}\right)_{2} \mathrm{Fe}\left(\mathrm{SO}_{4}\right)_{2} \cdot 6 \mathrm{H}_{2} \mathrm{O}$ [22]. The dissolved $\mathrm{Fe}^{2+}$ and $\mathrm{Fe}^{3+}$ concentrations in sediments were measured using $o$-phenanthroline spectrophotometry [23]. The total P (TP) concentration in sediments was determined using the ascorbic acid method [24]. Fe-P was graded according to the harmonized protocol of the Standards, Measurements, and Testing Programme of the European Commission [17] and was determined by molybdenum-antimony anti-spectrophotometry [24].

\subsection{Bacterial Community Analysis}

Total genomic DNA was extracted from $0.5 \mathrm{~g}$ frozen sediment samples using a PowerSoil DNA extraction kit (Qiagen Inc., Valencia, CA, USA) according to the manufacturer's instructions. Universal primers 338F (5'-ACTCCTACGGGAGGCAGCAG- $\left.3^{\prime}\right)$ and 806R (5'GGACTACHVGGGTWTCTAAT-3') were used to amplify the V3-V4 region of the bacterial $16 \mathrm{~S}$ rRNA gene [25]. PCR reactions were carried out in a total volume of $25 \mu \mathrm{L}$ on an Applied Biosystems MiniAmp Plus Thermal Cycler (Thermo Fisher Scientific, Waltham, MA, USA). After purification and quantification, the PCR products were sequenced on an Illumina MiSeq platform (Illumina, San Diego, CA, USA) using a 468 bp paired-end protocol.

\subsection{Data Analysis}

Bioinformatics analysis of high-throughput sequencing data was performed on the Majorbio I-Sanger Cloud Platform (http:/ / www.i-sanger.com; accessed on 11 May 2021). The effective sequences were clustered into operational taxonomic units (OTUs) at $97 \%$ sequence similarity [26]. The species of each OTU were annotated using the bacterial $16 \mathrm{~S}$ rRNA Silva database (Release132, http:/ / www.arb-silva.de; accessed on 14 May 2021) to obtain bacterial taxonomic information of each sample and the community species composition at each classification level. The OTU data were normalized, and the bacterial community diversity of each sample was analyzed in terms of observed number of species (Sobs), abundance-based coverage estimator (ACE), and Shannon diversity index, using Mothur [27].

Hierarchical clustering analysis of bacterial communities at the OTU level was performed in PRIMER 5 (PRIMER-E Limited, UK) based on the unweighted pair group method with arithmetic mean (UPGMA) method. Key bacterial taxa associated with Fe redox transformation were identified by comparing the results with data available in the National Center for Biotechnology Information (NCBI) database (https:/ / www.ncbi.nlm.nih.gov; accessed on 20 November 2021) and previously published articles [28,29]. Functional annotation of prokaryotic taxa (FAPROTAX) was carried out (http://www.zoology.ubc.ca/ 
louca/FAPROTAX/; accessed on 28 December 2021) to predict the potential functions of bacterial communities based on the 16S rRNA gene data [30].

Statistical analyses were performed in IBM SPSS Statistics 26 (IBM Corp., Armonk, NY, USA). Differences in sediment physicochemical properties, bacterial $\alpha$-diversity indexes, and dominant taxa abundance between samples were determined using one-way analysis of variance and Tukey's multiple comparison tests. $p<0.05$ was considered an indication of statistical significance. Redundancy analysis (RDA) was carried out using Canoco 5.02 (Microcomputer Power, Ithaca, NY, USA) to determine the environmental variables that best explained variation in bacterial community structure in sediments treated with $V$. natans planting and IOB inoculation.

\section{Results}

\subsection{Sediment pH, Organic Matter Content, and Redox Potential}

The $\mathrm{pH}$ in sediments of all treatments decreased from the transplanting to rapid growth and then mature stages of $V$. natans, with mean values of 7.92, 7.34, and 7.01, respectively (Figure 2a). In the later growth stages, $\mathrm{pH}$ exhibited decreasing trends under the three $V$. natans treatments (Va, Va-IOB, and Va-IOB[A]); however, there was no significant difference with the $\mathrm{pH}$ of the control treatment.
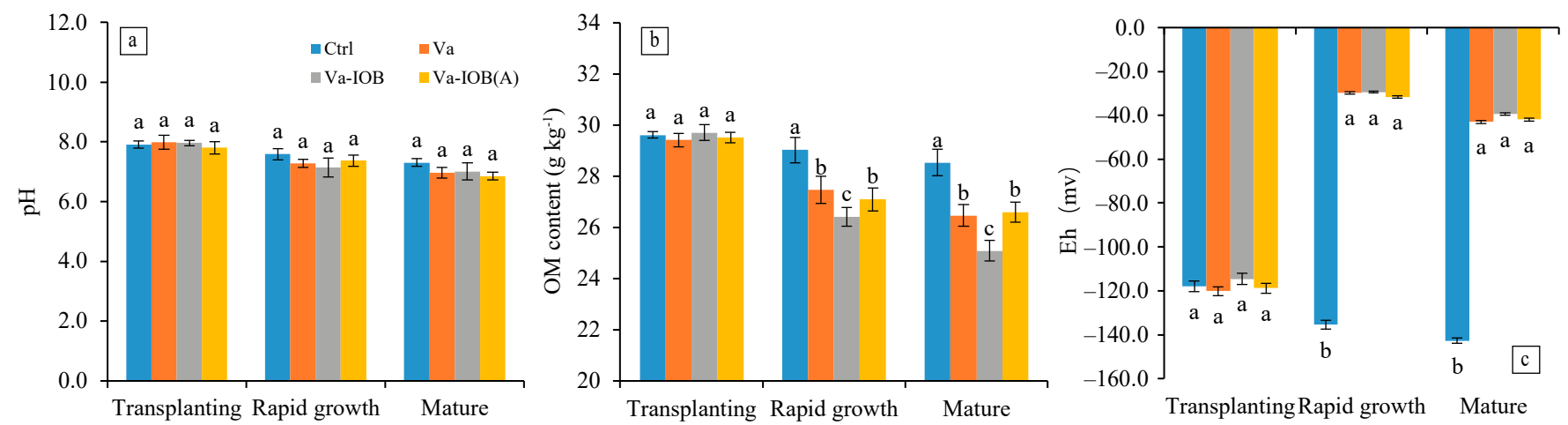

Figure 2. (a) $\mathrm{pH},(\mathbf{b})$ organic matter $(\mathrm{OM})$ content, and (c) redox potential (Eh) trends in sediments under different treatments during $V$. natans growth. Values are means \pm standard deviation. For each stage, different lowercase letters above or below bars indicate significant differences at the 0.05 significance level by Tukey's test.

The OM contents in sediments of all treatments also decreased from the transplanting stage to the mature stage (Figure $2 \mathrm{~b} ; p<0.05$ ). Sediment OM contents of the $V$. natans treatments were all significantly lower than that of the control treatment. In particular, the OM contents under the Va-IOB treatment were the lowest, in both the rapid growth and mature stages $(p<0.05)$.

Eh in sediments of the control treatment decreased significantly in the rapid growth and mature stages when compared with that in the transplanting stage $(p<0.05$; Figure $2 c)$. However, after $V$. natans planting, Eh increased significantly from the transplanting to rapid growth stage $(p<0.05)$, followed by a slight drop thereafter. No significant difference in Eh was observed between the treatments with and without IOB inoculation.

\subsection{Sediment Iron, Phosphorus, and Iron-Bound Phosphorus Concentrations}

With the exception of the control treatment, $\mathrm{Fe}^{2+}$ concentrations in sediments decreased from the transplanting stage to the mature stage $(p<0.05$; Figure $3 a)$. In the rapid growth and mature stages, $\mathrm{Fe}^{2+}$ concentrations under the Va-IOB treatment $\left(3.31\right.$ and $1.90 \mathrm{mg} \mathrm{kg}^{-1}$, respectively) were significantly lower than those under the Va and Va-IOB(A) treatments $(p<0.05)$. Conversely, $\mathrm{Fe}^{3+}$ concentrations in sediments treated with $V$. natans increased significantly from transplantation to maturity, with the highest values observed under the Va-IOB treatment in the later growth stages $(p<0.05$; Figure $3 \mathrm{~b})$. In the rapid growth 
and mature stages, the ratios between $\mathrm{Fe}^{3+}$ and $\mathrm{Fe}^{2+}$ concentrations increased markedly in sediments treated with $V$. natans, especially under the Va-IOB treatment $(p<0.05$; Figure $3 c)$.
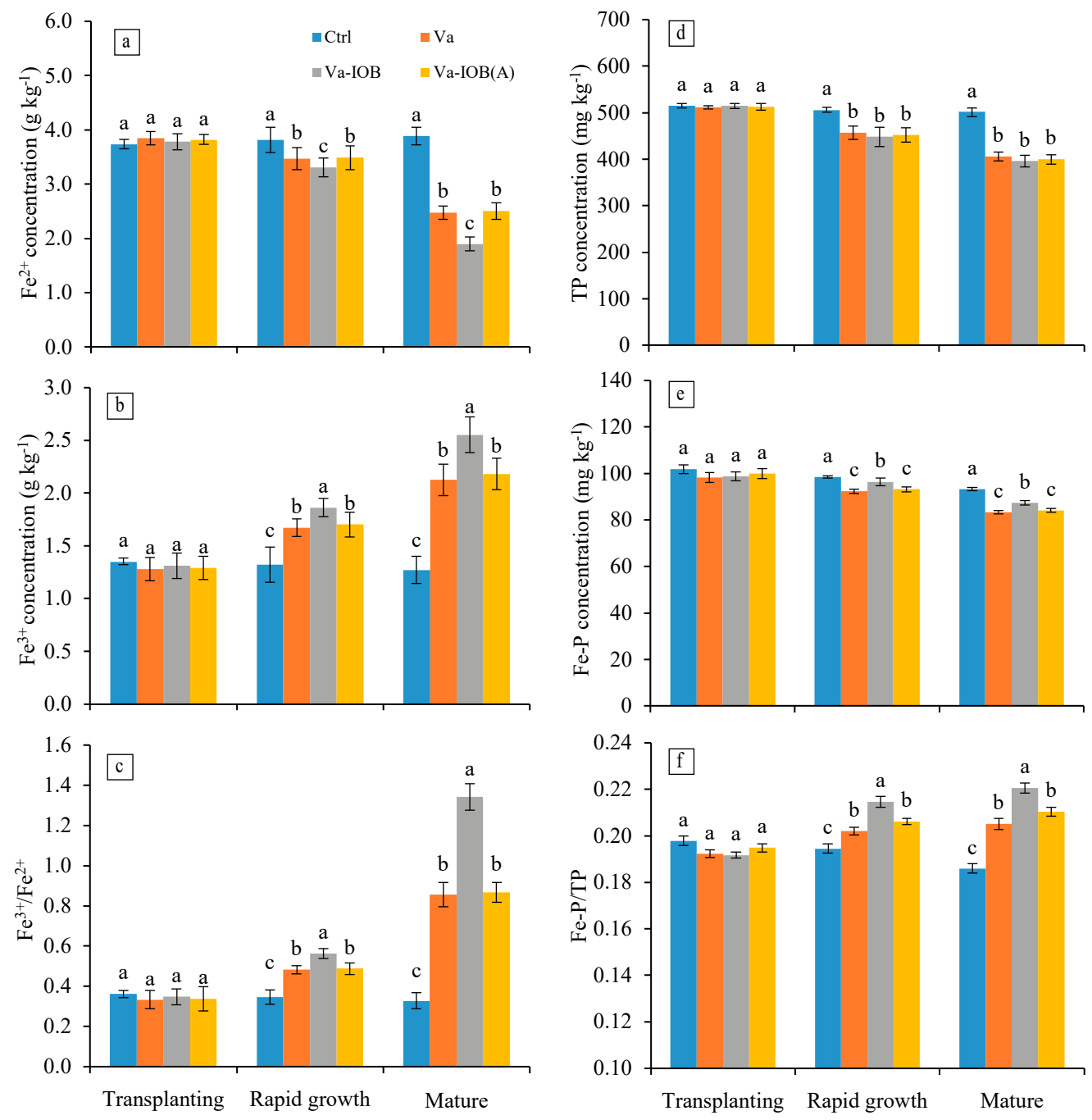

Figure 3. Iron and phosphorus concentrations in sediments under different treatments. (a) Dissolved $\mathrm{Fe}^{2+} ;$ (b) dissolved $\mathrm{Fe}^{3+} ;$ (c) ratios between $\mathrm{Fe}^{3+}$ and $\mathrm{Fe}^{2+} ;$ (d) total phosphorus (TP); (e) iron-bound phosphorus (Fe-P); and (f) proportions of Fe-P in TP (Fe-P/TP). Values are means \pm standard deviation. For each stage, different lowercase letters above bars indicate significant differences at the 0.05 significance level by Tukey's test.

Compared with the control treatment, TP concentrations in sediments treated with $V$. natans decreased significantly during the rapid growth and mature stages $(p<0.05$; Figure 3d). However, there were no significant differences in TP concentrations among the $\mathrm{Va}, \mathrm{Va}-\mathrm{IOB}$, and Va-IOB(A) treatments. Similarly, Fe-P concentrations had no significant differences between the $\mathrm{Va}$ and $\mathrm{Va}-\mathrm{IOB}(\mathrm{A})$ treatments in the later growth stages, with mean values of 92.75 and $83.65 \mathrm{mg} \mathrm{kg}^{-1}$, respectively, lower than that of the Va-IOB treatment (Figure 3e). During the later growth stages, the proportions of Fe-P in TP significantly increased in sediments treated with $V$. natans, and the highest value was observed under the Va-IOB treatment ( $p<0.05$; Figure 3f).

\subsection{Sediment Bacterial Diversity and Community Composition}

The calculated $\alpha$-diversity indexes of bacterial communities in sediment samples under different treatments are listed in Table 1. The Sobs and ACE indexes represent bacterial species richness, while the Shannon index represents bacterial species evenness; higher 
values of the $\alpha$-diversity indexes suggest greater bacterial richness and lower heterogeneity. Overall, the mean coverage among all the samples was 97.3\% (range: 95.1-98.7\%). From the transplanting to mature stages of $V$. natans, the Sobs and ACE indexes decreased under the control treatment but increased under the other treatments with $V$. natans. The patterns of the Shannon index among different stages and treatments were similar to those of the species richness indexes. In the rapid growth and mature stages, the lowest Sobs, ACE, and Shannon index values were observed under the control treatment, while the highest ACE and Shannon index values were observed under the Va-IOB treatment.

Table 1. $\alpha$-diversity of sediment bacterial communities evaluated based on operational taxonomic units (OTUs) clustered at the $97 \%$ similarity level.

\begin{tabular}{cccccc}
\hline Stage & Treatment & $\begin{array}{c}\text { Observed Number } \\
\text { of Species }\end{array}$ & $\begin{array}{c}\text { Abundance-Based } \\
\text { Coverage Estimator }\end{array}$ & Shannon Index & Coverage \\
\hline Transplanting & Ctrl & $1259.43 \mathrm{a}$ & $1409.15 \mathrm{a}$ & $5.27 \mathrm{a}$ & 0.980 \\
& Va & $1248.37 \mathrm{a}$ & $1418.30 \mathrm{a}$ & $5.32 \mathrm{a}$ & 0.966 \\
& Va-IOB & $1251.13 \mathrm{a}$ & $1397.05 \mathrm{a}$ & $5.24 \mathrm{a}$ & 0.987 \\
Rapid growth & Va-IOB(A) & $1251.40 \mathrm{a}$ & $1398.93 \mathrm{a}$ & $5.26 \mathrm{a}$ & 0.967 \\
& Ctrl & $1190.53 \mathrm{~b}$ & $1335.38 \mathrm{c}$ & $5.48 \mathrm{~b}$ & 0.980 \\
& Va & $1291.61 \mathrm{a}$ & $1456.95 \mathrm{~b}$ & $6.06 \mathrm{a}$ & 0.951 \\
Mature & Va-IOB & $1335.27 \mathrm{a}$ & $1481.73 \mathrm{a}$ & $5.45 \mathrm{~b}$ & 0.973 \\
& Va-IOB(A) & $1284.31 \mathrm{a}$ & $1451.00 \mathrm{~b}$ & $4.97 \mathrm{c}$ & 0.980 \\
& Ctrl & $1112.28 \mathrm{~b}$ & $1276.74 \mathrm{c}$ & $6.18 \mathrm{~b}$ & 0.977 \\
& Va & $1294.71 \mathrm{a}$ & $1513.42 \mathrm{~b}$ & $6.27 \mathrm{a}$ & 0.983 \\
\hline
\end{tabular}

Note: Ctrl, no V. natans planting or iron-oxidizing bacteria (IOB) inoculation; Va, planting V. natans without IOB inoculation; Va-IOB, planting V. natans with $\mathrm{IOB}$ inoculation; Va-IOB(A), planting V. natans with autoclaved IOB inoculation. For each stage, different lowercase letters in the same column indicate significant differences among the treatments based on Tukey's test $(p<0.05)$

Based on the results of unweighted UniFrac distance analysis, sediment bacteria were clustered into three groups ( $p<0.05$; Figure 4 ). Excluding the control, all samples were clearly separated in groups corresponding to $V$. natans growth stages. Group I contained $\mathrm{Va}, \mathrm{Va}-\mathrm{IOB}$, and $\mathrm{Va}-\mathrm{IOB}(\mathrm{A})$ samples of the rapid growth stage and control samples of the mature stage; group II contained the control, Va, Va-IOB, and Va-IOB(A) samples of the transplanting stage and control samples of the rapid growth stage; and group III contained $\mathrm{Va}, \mathrm{Va}-\mathrm{IOB}$, and $\mathrm{Va}-\mathrm{IOB}(\mathrm{A})$ samples of the mature stage. Among the retrieved OTUs, $86.0-91.5 \%$ were classified among the top 10 most abundant bacterial phyla. The most abundant phylum was Proteobacteria in group I (38.7\% of the total sequences), Proteobacteria in group II (48.9\%), and Firmicutes in group III (38.7\%). From transplanting to maturity, the relative abundance of Proteobacteria decreased substantially, while an increasing trend was observed for Firmicutes in all treatments. Compared with the control treatment, a higher relative abundance of Firmicutes was observed under the $V$. natans treatments $(\mathrm{Va}, \mathrm{Va}-\mathrm{IOB}$, and $\mathrm{Va}-\mathrm{IOB}[\mathrm{A}])$ in both the rapid growth and mature stages.

RDA was performed to explore the correlations between the relative abundances of bacterial phyla and sediment physicochemical properties. The model attributed $94.8 \%$ of the variance to phyla-environment correlations (Figure 5). The first and second axes accounted for $67.5 \%$ and $22.3 \%$ of the variation, respectively. In addition, $\mathrm{Fe}-\mathrm{P}, \mathrm{TP}, \mathrm{pH}$, and OM were the key factors significantly influencing bacterial community structure $(p<0.05)$. 


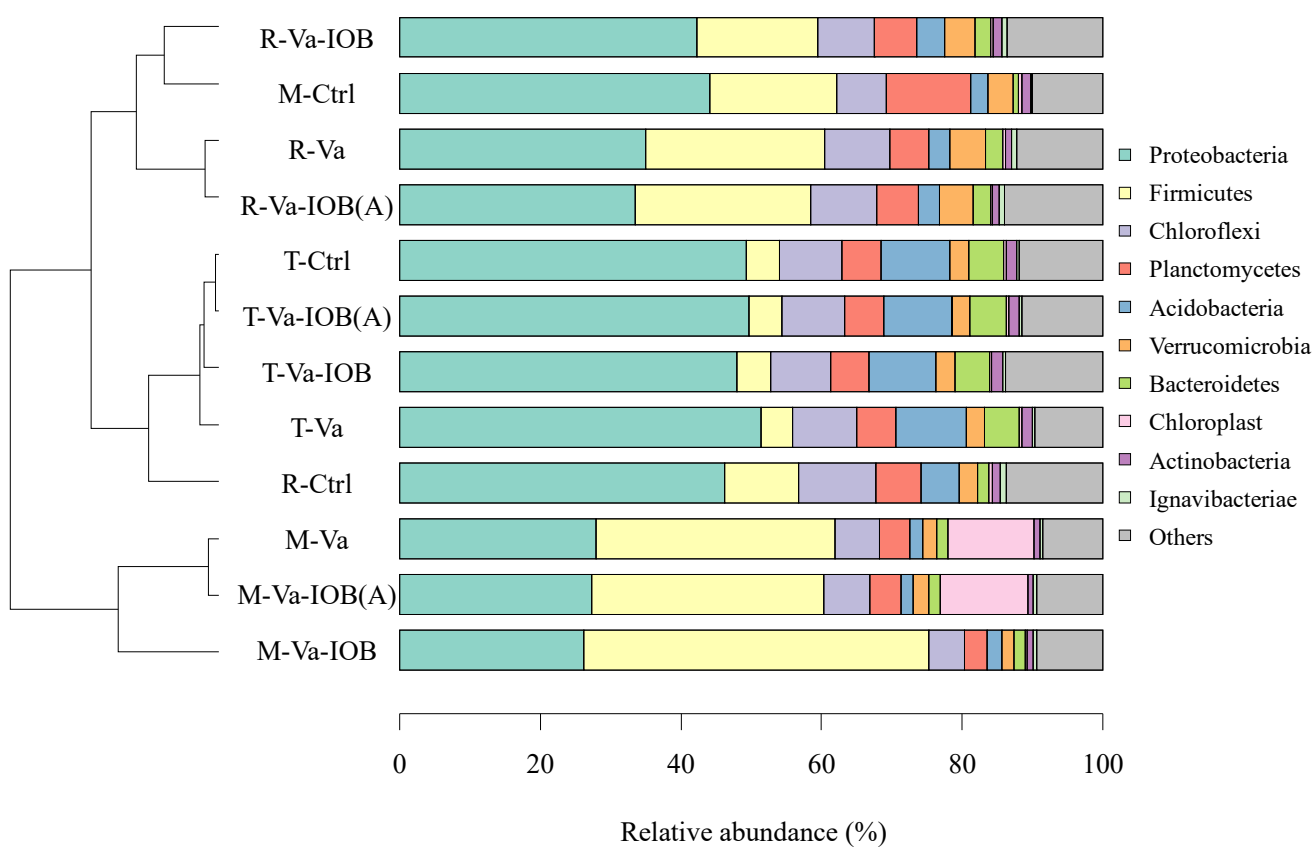

Figure 4. Clustering analysis of bacterial communities at the operational taxanomic unit (OTU) level (left) and bacterial community composition at the phylum level (right) in sediments under different treatments. T-, R-, and M- denote the transplanting, rapid growth, and mature stages of $V$. natans, respectively. Hierarchical clustering analysis was performed using unweighted pair group method with arithmetic mean (UPGMA) based on unweighted UniFrac distances from taxa tables and OTU number. The top 10 most abundant bacterial phyla are shown.

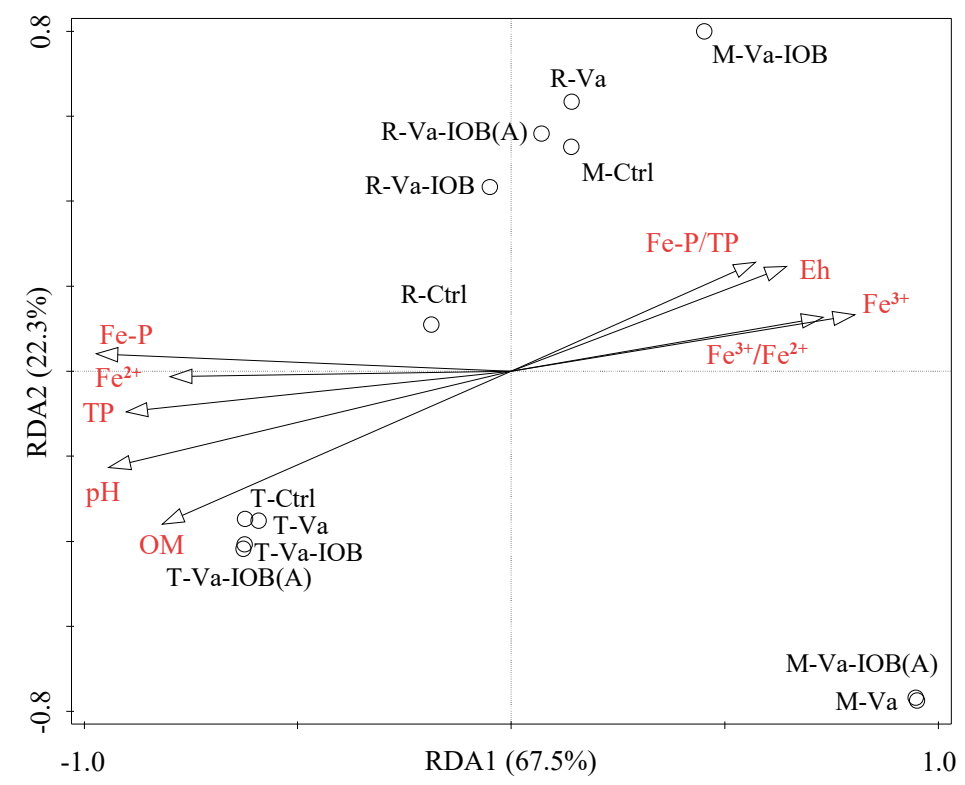

Figure 5. Redundancy analysis (RDA) ordination bi-plot showing the relationships between bacterial community structure (phylum level) and sediment environmental variables. OM, organic matter; Eh, redox potential; TP, total phosphorus; Fe-P, iron-bound phosphorus. Black circles represent treatments at different $V$. natans growth stages: T, transplanting; R, rapid growth; M, mature.

\subsection{Bacterial Taxa and Functional Genes Related to Iron Oxidation and Reduction}

The dominant IOB at the genus level in all treatments included Acidovorax and Chlorobium, especially in the rapid growth stage. The relative abundances of IOB increased markedly from the transplanting to rapid growth stage and then decreased toward the ma- 
ture stage (Figure 6a). In the later growth stages, the highest relative abundance of IOB was observed under the Va-IOB treatment. In contrast, the relative abundances of $\mathrm{Fe}^{3+}$-reducing bacteria (IRB) decreased substantially from transplantation to maturity (Figure 6b). In the rapid growth and mature stages, the relative abundances of IRB under the Va-IOB treatment were lower than those of other treatments. In addition, the IOB/IRB ratios in sediments treated with $V$. natans considerably increased in the later growth stages, and the highest ratio was observed under the Va-IOB treatment (Figure 6c).
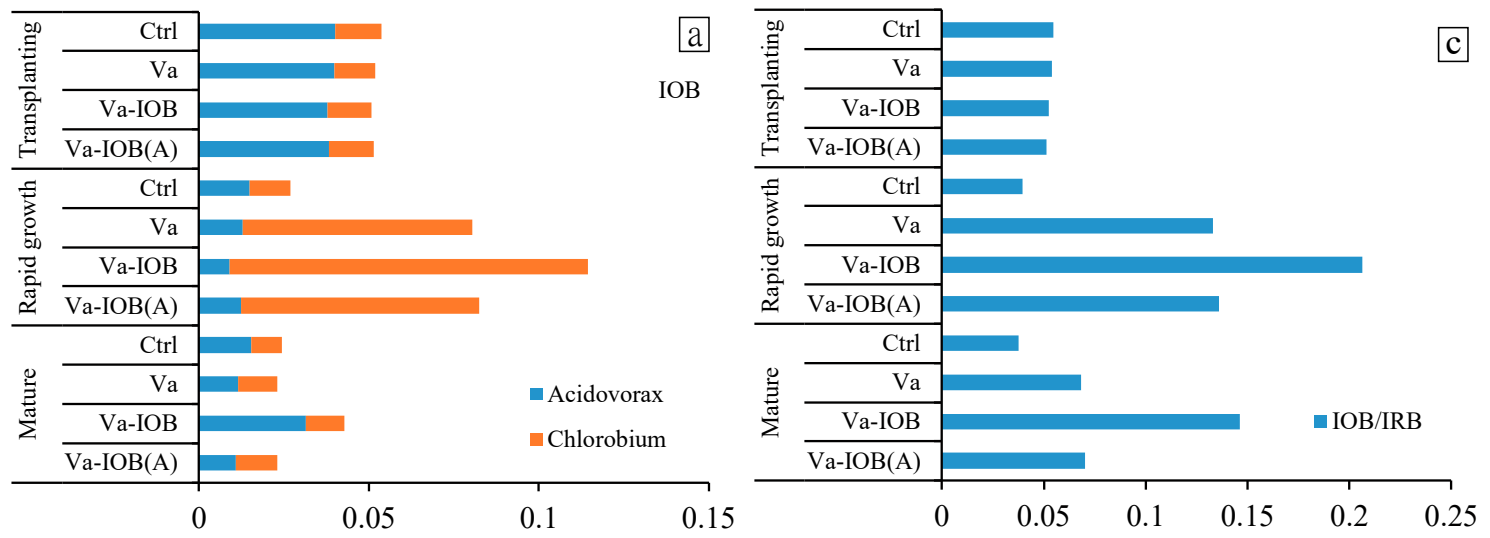

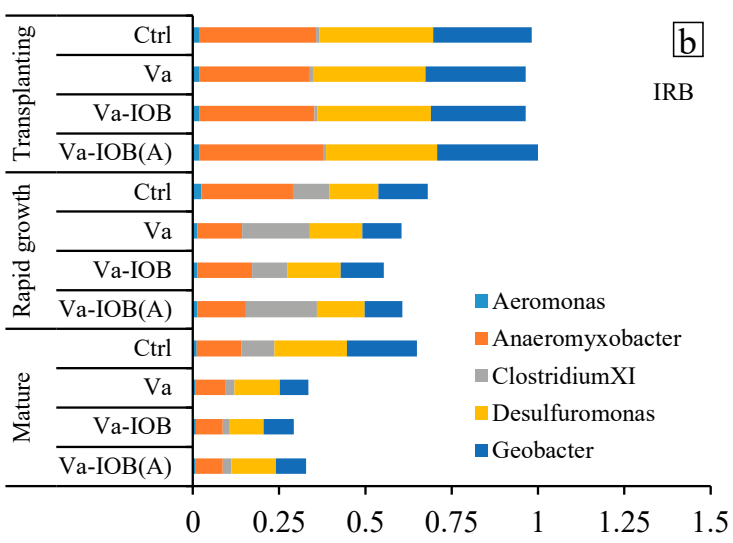

Relative abundance (\%)

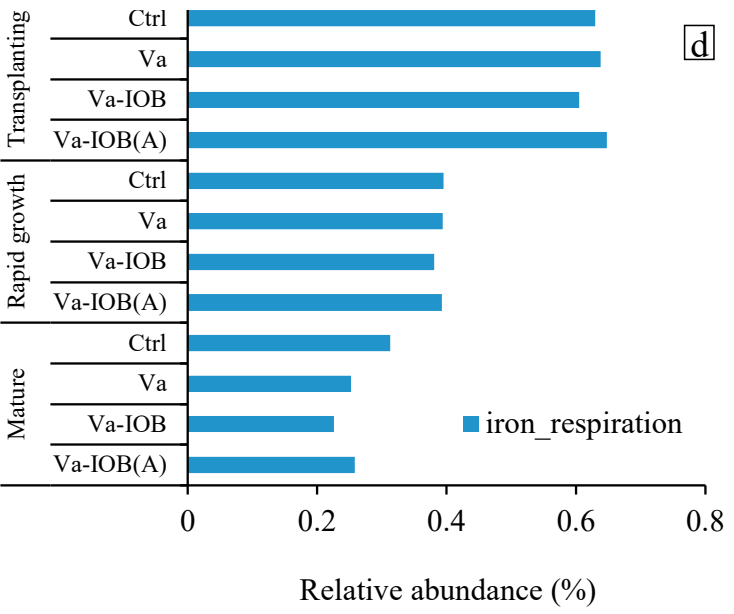

Relative abundance $(\%)$

Figure 6. Key bacterial genera related to (a) iron oxidation and (b) iron reduction, $(\mathbf{c})$ the ratio between iron-oxidizing bacteria (IOB) and iron-reducing bacteria (IRB), and (d) FAPROTAX-based functional prediction of sediment bacteria related to iron respiration under different treatments.

Potentially related functions among bacterial communities were predicted using FAPROTAX 1.1, and the relative contributions of each functional bacterial group were explored (Figure 6d). The relative abundances of genes related to Fe reduction decreased considerably from transplantation to maturity. In particular, the relative abundances of Fe reduction-related genes were distinctively lower under the Va-IOB treatment compared with the other treatments at maturity. However, key ecological functions related to Fe oxidation were not predicted in any treatments.

\section{Discussion}

4.1. Synergistic Interactions of V. natans and Iron-Oxidizing Bacteria Enhance Iron-Bound Phosphorus Formation in Sediments

In the present study, we investigated the combined effects of $V$. natans growth and IOB inoculation on internal P loading from eutrophic lake sediments. We observed that TP concentrations in sediments decreased remarkably after the planting of $V$. natans with and without IOB inoculation. The results indicate that $V$. natans could control internal 
$\mathrm{P}$ loading by absorbing $\mathrm{P}$ from sediments. Our finding is consistent with the results of previous studies where only treatments with submerged macrophyte plantations could control internal P loading [4-6]. In another study, compared with the unplanted control, TP concentrations in sediments planted with V. natans and Ceratophyllum demersum decreased by $10.7 \%$ and $9.9 \%$, respectively [31].

$\mathrm{P}$ migration in shallow eutrophic lake sediments is mainly regulated by redox transformation of Fe [32]. On the one hand, restoration of submerged macrophytes has the potential to increase sediment $\mathrm{Eh}$ and to enhance the oxidation of $\mathrm{Fe}^{2+}$ to $\mathrm{Fe}^{3+}$, leading to Fe-P formation and ultimately facilitating sediment $P$ retention [33]. On the other hand, labile root exudates from submerged macrophytes could activate anaerobic organic matter-degrading bacteria, which might participate in biological reduction of $\mathrm{Fe}^{3+}$ or provide substrates for a chemical reduction of $\mathrm{Fe}^{3+}$, resulting in an increase in P release [15]. Here, planting V. natans with and without IOB inoculation enhanced Fe-P formation and increased the proportions of Fe-P in TP in sediments, indicating that Fe oxidation, rather than Fe reduction, is the dominant process.

In addition to chemical Fe oxidation, bacterially mediated Fe oxidation considerably enhanced Fe-P formation in the sediments. The biological effect was demonstrated by increases in the concentrations of $\mathrm{Fe}-\mathrm{P}$ and proportions of $\mathrm{Fe}-\mathrm{P}$ in TP under the Va-IOB treatment compared with the $\mathrm{Va}$ and $\mathrm{Va}-\mathrm{IOB}(\mathrm{A})$ treatments. Multiple factors including $\mathrm{OM}$, Eh, and dissolved oxygen influence the dynamics of IOB and IRB [34]. A previous study reported that higher Eh conditions are favorable for bacterially mediated Fe oxidation; the resulting FeOOH colloids can strongly absorb $\mathrm{PO}_{4}{ }^{3-}$ and can enhance Fe-P formation [35]. Similarly, we detected relatively high $\mathrm{Eh}, \mathrm{Fe}^{3+}$ concentrations, and $\mathrm{Fe}^{3+} / \mathrm{Fe}^{2+}$ ratios under the Va-IOB treatment. This was probably caused by rapid Fe redox transformations mediated by the introduction of the IOB consortium, which thus enhanced the formation of Fe-bound P precipitates [36]. In summary, the results indicate that the synergistic interactions between $V$. natans and IOB enhanced Fe-P formation in sediments.

\subsection{Synergistic Interactions of $V$. natans and Iron-Oxidizing Bacteria Increase Diversity of Sediment Bacterial Community}

In the present study, the $V$. natans planting treatments with and without IOB inoculation increased the $\alpha$-diversity of bacterial communities in sediments, especially in the rapid growth and mature stages. Such improvements in bacterial diversity could be attributed to lower OM contents in sediments planted with $V$. natans. Similarly, Lin et al. [4] observed that bacterial community diversity in macrophyte-treated sediments was higher than that in unplanted controls. Another study reported a negative correlation between bacterial community diversity and OM content in sediments at seven sampling sites in Taihu Lake, China [37]. Higher OM concentrations may favor the growth of dominant bacterial populations, which in turn inhibits the growth of non-dominant bacteria [38].

The results of clustering analysis at the OTU level indicated that transplantation and growth of $V$. natans plants distinctively altered bacterial community structure in sediments. $V$. natans planting with and without IOB inoculation led to the enrichment of Firmicutes in the rapid growth and mature stages. The phylum Firmicutes contains a variety of bacteria capable of degrading and transforming organic material, thereby enhancing the release of mineral elements [39]. Therefore, the higher relative abundance of Firmicutes in sediments planted with $V$. natans (without additional nutrient input) might enhance OM decomposition and provide nutrients for $V$. natans growth.

\subsection{Key Taxa and Predicted Functions of Bacteria Associated with Phosphorus Retention in Sediments}

Although environmental physicochemical factors play a key role in Fe redox activity, an increasing number of studies report that some bacterial groups exert major influence in the transition between $\mathrm{Fe}^{2+}$ and $\mathrm{Fe}^{3+}[15,40]$. Numerous bacterial groups are capable of $\mathrm{Fe}$ reduction or oxidation in microaerobic and anaerobic environments [40]. The introduction of IOB and associated Fe oxides clearly increased the proportions of IOB in sediments 
during the rapid growth and mature stages of $V$. natans. This study identified the key bacterial genera associated with Fe redox transformation in sediments. Under all treatments, Acidovorax and Chlorobium were observed as dominant IOB. Members of Acidovorax, such as strains BoFeN1 and 2AN, are neutrophilic, nitrate $\left(\mathrm{NO}_{3}{ }^{-}\right)$-reducing, and $\mathrm{Fe}^{2+}$-oxidizing bacteria in anaerobic environments [41,42]. Therefore, $\mathrm{NO}_{3}{ }^{-}$reduction would also play a role in Fe oxidation in the simulated lake system. In addition, our previous field study showed that $\mathrm{N}$ metabolism genes accounted for a substantial portion of genes related to energy metabolism in shallow lake sediments [36]. However, none of the bacterial groups in all treatments was predicted to have potential Fe-oxidizing genes. These bacteria might be omitted in predictions of Fe oxidation function using FAPROTAX 1.1. A previous study also indicated that the abundance of traditional IOB was substantially low in all sediment samples, and they were almost absent in samples with OM addition [17].

Some bacterial groups with sulfide oxidation or sulfate reduction capacity influence the formation of Fe redox species through the transformation of sulfide [15]. In the present study, the trends in the relative abundances of IOB among different treatments were similar to those of sulfide-oxidizing bacteria (Figure S1a), while the relative abundances of IRB and sulfate-reducing bacteria (Figure S1b) shared similar trends. Furthermore, the relative abundances of predicted functions, including sulfur (S) oxidation and $\mathrm{N}$ reduction, were higher in sediments planted with $V$. natans, especially under the Va-IOB treatment (Figure S2a). Such trends were similar to those of IOB, while the trends in the relative abundances of predicted functions associated with $\mathrm{Fe}^{3+}$ reduction (Figure S2b) were similar to those of IRB. Sulfide could simultaneously reduce $\mathrm{Fe}^{3+}$ and form FeS; hence, it reduces the availability of Fe to bind P in both ferric and ferrous solids [15]. Given the high portion of sulfate-reducing bacteria (e.g., Desulfobacteraceae) in the sediment samples, the contribution of these microorganisms to Fe-P formation could not be neglected.

Overall, the results of the present study indicate that bacterially mediated Fe redox reactions play essential roles in the retention of $\mathrm{P}$ in sediments with the presence of $V$. natans. That $\mathrm{P}$ retention in sediments is synergistically controlled by Fe oxidation, $\mathrm{S}$ oxidation, and $\mathrm{NO}_{3}{ }^{-}$reduction. The underlying microbiological mechanisms of such synergistic interactions still require further investigations.

\section{Conclusions}

This study analyzed the interactive effects of $V$. natans planting and IOB inoculation on $\mathrm{Fe}-\mathrm{P}$ formation in eutrophic lake sediments. $V$. natans growth decreased $\mathrm{OM}, \mathrm{Fe}^{2+}$, and TP concentrations; increased $\mathrm{Fe}^{3+}$ and $\mathrm{Fe}-\mathrm{P}$ concentrations; and improved bacterial diversity in sediments. The effects of $V$. natans were dependent on plant growth stage intensified by IOB inoculation. Moreover, $V$. natans and IOB introduction increased the relative abundances of IOB genera, such as Acidovorax and Chlorobium, especially in the rapid growth stage of $V$. natans. The results confirm our hypothesis that synergistic interactions of $V$. natans growth and IOB activity enhance Fe-P formation in eutrophic lake sediments through the modification of sediment physicochemical conditions and associated bacterial community structure. Overall, the coupled $V$. natans-IOB system shows great potential as an in situ remediation technology for controlling internal $P$ loading from freshwater sediments. Our study was conducted under simulated conditions; therefore, the results must be interpreted with caution. Field experiments should be carried out to determine the optimal planting density of $V$. natans and inoculum level of IOB. Further studies on the key environmental factors and microbial taxa that influence the remediation process are also required to elucidate the microbiological mechanisms of IOB-mediated P retention in eutrophic sediments.

Supplementary Materials: The following are available online at https:/ /www.mdpi.com/article/10.3 390/microorganisms10020413/s1, Figure S1: Key bacterial genera related to (a) sulfide oxidation and (b) sulfate reduction in sediments under different treatments. Figure S2: Functional predictions of sediment bacteria related to (a) iron oxidation and (b) iron reduction by FAPROTAX. 


\begin{abstract}
Author Contributions: Conceptualization, J.W. and G.W.; methodology, J.W. and G.W.; software, J.W., G.W., S.L. and X.Q.; validation, J.W.; formal analysis, G.W.; investigation, J.W., M.G., Y.Y., S.L. and X.Q.; writing—original draft preparation, J.W., G.W. and M.G.; visualization, J.W., Y.Y., S.L. and G.W.; supervision, J.W. and G.W.; project administration, J.W., G.W. and X.Q.; funding acquisition, J.W. and X.Q. All authors have read and agreed to the published version of the manuscript.
\end{abstract}

Funding: This work was supported by the Natural Science Foundation of China (41701093) and the China Postdoctoral Science Foundation (2017M611928).

Institutional Review Board Statement: Not applicable.

Informed Consent Statement: Not applicable.

Data Availability Statement: The data presented in this study are available from the corresponding author upon request.

Conflicts of Interest: The authors declare no conflict of interest.

\title{
References
}

1. Song, K.; Burgin, A.J. Perpetual phosphorus cycling: Eutrophication amplifies biological control on internal phosphorus loading in agricultural reservoirs. Ecosystems 2017, 20, 1483-1493. [CrossRef]

2. Levine, S.N.; Lini, A.; Ostrofsky, M.L.; Burgess-Grant, H.; Lami, A.; Collyer-Gilles, E.; Reuter, D.; Schwarting-Miller, L.; Kamman, $\mathrm{N}$. The relative roles of point and nonpoint phosphorus sources in the eutrophication of Lake Champlain as recorded in sediment cores. J. Great Lakes Res. 2018, 44, 1043-1056. [CrossRef]

3. Cui, J.Z.; Jin, Z.F.; Wang, Y.; Gao, S.S.; Fu, Z.; Yang, Y.W.; Wang, Y. Mechanism of eutrophication process during algal decomposition at the water/sediment interface. J. Clean. Prod. 2021, 309, 127175. [CrossRef]

4. Lin, Q.; Fan, M.; Peng, X.; Ma, J.; Zhang, Y.; Yu, F.; Wu, Z.; Liu, B. Response of Vallisneria natans to aluminum phytotoxicity and their synergistic effect on nitrogen, phosphorus change in sediments. J. Hazard. Mater. 2020, 400, 123167. [CrossRef]

5. Wang, C.; Liu, S.Y.; Zhang, Y.; Liu, B.Y.; Zeng, L.; He, F.; Zhou, Q.H.; Wu, Z.B. Effects of planted versus naturally growing Vallisneria natans on the sediment microbial community in West Lake, China. Microb. Ecol. 2017, 74, 278-288. [CrossRef]

6. Zhang, L.L.; Zhang, Y.P.; Liu, L.Z. Effect of submerged macrophytes Vallisneria spiralis L. on restoring the sediment contaminated by enrofloxacin in aquaculture ponds. Ecol. Eng. 2019, 140, 105596. [CrossRef]

7. Fan, X.F.; Xing, X.G.; Ding, S.M. Enhancing the retention of phosphorus through bacterial oxidation of iron or sulfide in the eutrophic sediments of Lake Taihu. Sci. Total Environ. 2021, 791, 148039. [CrossRef]

8. Xu, P.; Xiao, E.R.; Zeng, L.; He, F.; Wu, Z.B. Enhanced degradation of pyrene and phenanthrene in sediments through synergistic interactions between microbial fuel cells and submerged macrophyte Vallisneria spiralis. J. Soils Sediments 2019, 19, $2634-2649$. [CrossRef]

9. Yang, Y.; Chen, W.; Yi, Z.Y.; Pei, G.F. The integrative effect of periphyton biofilm and tape grass (Vallisneria natans) on internal loading of shallow eutrophic lakes. Environ. Sci. Pollut. Res. 2018, 25, 1773-1783. [CrossRef]

10. Yang, H.Q.; He, K.K.; Lu, D.P.; Wang, J.F.; Xu, D.; Jin, Z.X.; Yang, M.X.; Chen, J.G. Removal of phosphate by aluminum-modified clay in a heavily polluted lake, Southwest China: Effectiveness and ecological risks. Sci. Total Environ. 2020, 705, 135850. [CrossRef]

11. Li, S.J.; Lin, Z.G.; Liu, M.; Jiang, F.Z.; Chen, J.; Yang, X.G.; Wang, S.X. Effect of ferric chloride on phosphorus immobilization and speciation in Dianchi Lake sediments. Ecotoxicol. Environ. Saf. 2020, 197, 110637. [CrossRef] [PubMed]

12. Bai, X.Y.; Lin, J.W.; Zhan, Y.H.; Chang, M.Y.; Xin, H.M.; Wu, J.L. Use of lron-modified calcite as an active capping material to control phosphorus release from sediments in surface water bodies. Environ. Sci. 2020, 41, 1296-1307. [CrossRef]

13. Jamal, R.; Mubarak, S.; Sahulka, S.Q.; Kori, J.A.; Tajammul, A.; Ahmed, J.; Mahar, R.B.; Olsen, M.S.; Goel, R.; Weidhaas, J. Informing water distribution line rehabilitation through quantitative microbial risk assessment. Sci. Total Environ. 2020, 739, 140021. [CrossRef] [PubMed]

14. Ramezani, M.; Enayati, M.; Ramezani, M.; Ghorbani, A. A study of different strategical views into heavy metal(oid) removal in the environment. Arab. J. Geosci. 2021, 14, 2225. [CrossRef]

15. Fan, X.F.; Ding, S.M.; Gong, M.D.; Chen, M.S.; Gao, S.S.; Jin, Z.F.; Tsang, D.C.W. Different influences of bacterial communities on Fe(III) reduction and phosphorus availability in sediments of the cyanobacteria- and macrophyte-dominated zones. Front. Microbiol. 2018, 9, 2636. [CrossRef]

16. Smolders, E.; Baetens, E.; Verbeeck, M.; Nawara, S.; Diels, J.; Verdievel, M.; Peeters, B.; De Cooman, W.; Bakens, S. Internal loading and redox cycling of sediment iron explain reactive phosphorus concentrations in lowland rivers. Environ. Sci. Technol. 2017, 51, 2584-2592. [CrossRef]

17. Wang, Z.C.; Huang, S.; Li, D.H. Decomposition of cyanobacterial bloom contributes to the formation and distribution of ironbound phosphorus (Fe-P): Insight for cycling mechanism of internal phosphorus loading. Sci. Total Environ. 2019, 652, 696-708. [CrossRef] 
18. Holmes, D.E.; Bond, D.R.; Lovley, D.R. Electron transfer by Desulfobulbus propionicus to Fe(III) and graphite electrodes. Appl. Environ. Microbiol. 2004, 70, 1234-1237. [CrossRef]

19. Li, H.; Song, C.L.; Cao, X.Y.; Zhou, Y.Y. The phosphorus release pathways and their mechanisms driven by organic carbon and nitrogen in sediments of eutrophic shallow lakes. Sci. Total Environ. 2016, 572, 280-288. [CrossRef]

20. Chen, F.X.; Lu, S.; Deng, Y.; Feng, C.; Chen, N.; Guo, H.M. Different forms of phosphorous transformation and release prediction with environment factor in sediments from Lake Dongting, China. Desalin. Water Treat. 2021, 214, 402-412. [CrossRef]

21. Wang, J.J.; Muyzer, G.; Bodelier, P.L.E.; Laanbroek, H.J. Diversity of iron oxidizers in wetland soils revealed by novel 16S rRNA primers targeting Gallionella-related bacteria. ISME J. 2009, 3, 715-725. [CrossRef] [PubMed]

22. Xue, W.L.; Pan, W.; Lu, Q.; Xu, Q.R.; Wu, C.N.; Du, S.T. Aquatic plant debris changes sediment enzymatic activity and microbial community structure. Environ. Sci. Pollut. Res. 2018, 25, 21801-21810. [CrossRef] [PubMed]

23. Kostka, J.E.; Luther, G.W. Partitioning and speciation of solid phase iron in saltmarsh sediments. Geochim. Cosmochim. AC 1994, 58, 1701-1710. [CrossRef]

24. Bao, S.D. Soil Agro-Chemistrical Analysis, 3rd ed.; China Agriculture Press: Beijing, China, 2007; pp. $268-270$.

25. Dennis, K.L.; Wang, Y.W.; Blatner, N.R.; Wang, S.Y.; Saadalla, A.; Trudeau, E.; Roers, A.; Weaver, C.T.; Lee, J.J.; Gilbert, J.A.; et al. Adenomatous polyps are driven by microbe-instigated focal inflammation and are controlled by il-10-producing t cells. Cancer Res. 2013, 73, 5905-5913. [CrossRef] [PubMed]

26. Stackebrandt, E.; Goebel, B.M. Taxonomic note, a place for DNA-DNA reassociation and 16S rRNA sequence analysis in the present species definition in bacteriology. Int. J. Syst. Bacteriol. 1994, 44, 846-849. [CrossRef]

27. Schloss, P.D.; Westcott, S.L.; Ryabin, T.; Hall, J.R.; Hartmann, M.; Hollister, E.B.; Lesniewski, R.A.; Oakley, B.B.; Parks, D.H.; Robinson, C.J.; et al. Introducing Mothur: Open-source, platform-independent, community-supported software for describing and comparing microbial communities. Appl. Environ. Microbiol. 2009, 75, 7537-7541. [CrossRef] [PubMed]

28. Liu, T.X.; Chen, D.D.; Li, X.M.; Li, F.B. Microbially mediated coupling of nitrate reduction and Fe(II) oxidation under anoxic conditions. FEMS. Microbiol. Ecol. 2019, 95, fiz030. [CrossRef]

29. Kappler, A.; Bryce, C.; Mansor, M.; Lueder, U.; Byrne, J.M.; Swanner, E.D. An evolving view on biogeochemical cycling of iron. Nat. Rev. Microbiol. 2021, 19, 360-374. [CrossRef]

30. Louca, S.; Parfrey, L.W.; Doebeli, M. Decoupling function and taxonomy in the global ocean microbiome. Science 2016, 353, 1272-1277. [CrossRef]

31. Dai, Y.R.; Wu, J.; Zhong, F.; Cui, N.X.; Kong, L.W.; Liang, W.; Cheng, S.P. Macrophyte identity shapes water column and sediment bacterial community. Hydrobiologia 2019, 835, 71-82. [CrossRef]

32. Ding, S.; Wang, Y.; Wang, D.; Li, Y.Y.; Gong, M.; Zhang, C. In situ, high-resolution evidence for iron-coupled mobilization of phosphorus in sediments. Sci. Rep. 2016, 6, 24341. [CrossRef] [PubMed]

33. Peng, J.F.; Wang, B.Z.; Song, Y.H.; Yuan, P.; Liu, Z.H. Adsorption and release of phosphorus in the surface sediment of a wastewater stabilization pond. Ecol. Eng. 2007, 31, 92-97. [CrossRef]

34. Konhauser, K.O.; Kappler, A.; Roden, E.E. Iron in microbial metabolisms. Elements 2011, 7, 89-93. [CrossRef]

35. Chen, M.; Sun, H.Q.; Jiang, H.L. The addition of FeOOH binds phosphate in organic matter-rich sediments. Chem. Ecol. 2016, 32, 432-445. [CrossRef]

36. Wang, J.J.; Zhang, S.W.; Que, T.Y.; Kaksonen, A.H.; Qian, X.Q.; Zhuang, X.L.; Bohu, T. Mitigation of eutrophication in a shallow lake: The influences of submerged macrophytes on phosphorus and bacterial community structure in sediments. Sustainability 2021, 13, 9833. [CrossRef]

37. Chen, N.; Yang, J.S.; Qu, J.H.; Li, H.F.; Liu, W.J.; Li, B.Z.; Wang, E.T.; Yuan, H.L. Sediment prokaryote communities in different sites of eutrophic Lake Taihu and their interactions with environmental factors. World J. Microbiol. Biotechnol. 2015, 31, 883-896. [CrossRef] [PubMed]

38. Hibbing, M.E.; Fuqua, C.; Parsek, M.R.; Peterson, S.B. Bacterial competition: Surviving and thriving in the microbial jungle. Nat. Rev. Microbiol. 2010, 8, 15-25. [CrossRef]

39. Goffredi, S.K.; Orphan, V.J. Bacterial community shifts in taxa and diversity in response to localized organic loading in the deep sea. Environ. Microbiol. 2010, 12, 344-363. [CrossRef]

40. Weber, K.A.; Achenbach, L.A.; Coates, J.D. Microorganisms pumping iron: Anaerobic microbial iron oxidation and reduction. Nat. Rev. Microbiol. 2006, 4, 752-764. [CrossRef]

41. Price, A.; Macey, M.C.; Miot, J.; Olsson-Francis, K. Draft genome sequences of the nitrate-dependent iron-oxidizing Proteobacteria Acidovorax sp. strain BoFeN1 and Paracoccus pantotrophus strain KS1. Microbiol. Resour. Announc. 2018, 7, e01050-18. [CrossRef]

42. Chakraborty, A.; Roden, E.E.; Schieber, J.; Picardal, F. Enhanced growth of Acidovorax sp. strain 2AN during nitrate-dependent Fe(II) oxidation in batch and continuous-flow systems. Appl. Environ. Microbiol. 2011, 77, 8548-8556. [CrossRef] [PubMed] 